\title{
Peanut Butter, Salmonella Poisoning and Childrem: On Becoming 'Involved' amd Angry Following a Company Crisis
}

\author{
Lyn McDonald and Charmine E.J. Härtel
}

Imagine the following scenario: your six-year-old daughter has come home sick from primary school with stomach cramps, diarrhoea and vomiting. You envisage a touch of gastro-enteritis - after all, it is common in kids - and expect it to blow over quickly. She's off her food and will only eat a few things, including peanut butter on toast. After a few days, her condition has worsened to the point that your family GP is considering hospitalising her. Later, you hear on the radio that Kraft, which initially only recalled eight brands of peanut butter, is recalling its entire peanut butter range due to possible contamination with salmonella bacteria from mouse droppings found in batches of roasted peanuts from a Kingaroy supplier $(B R W 2.9 .96)$. If this were you, chances are that you would feel angry because it is your daughter who has been affected. You are involved.

Now consider that you are a person who never eats peanut butter. If that is the case, perhaps this incident, reported as 'Australia's biggest food scare' (The Age 27.6.96), received only your passing attention. Despite the fact that 540 Australians filed for legal action following this mishap ( $B R W$ 2.9.96), including a number of Queenslanders, any emotional reaction you felt is likely to have been short-lived since the crisis did not involve you. On the other hand, when you heard media allegations that implicated petroleum company, the Royal Dutch/Shell Group of Companies, in deaths of consumer activists and villagers, gun-running and massive environmental damage in Nigeria, you may have been outraged, vowing never to fill up at a Shell service station again ('The price of petrol,' SBS TV 21.1.97).

These scenarios illustrate the argument in this paper, which is that consumer anger is predicated upon the strength of each consumer's personal involvement with an individual company crisis. The more a crisis impinges on the values, interests and concerns of the wider community, the greater the consumer action against a company, reflected in plummeting sales. For companies, the implication is that 
managers must not only be aware of their company's legal obligations, but they must also be familiar with the general public's expectations regarding the responsibilities of business. Companies must remain vigilant so that they correctly identify community values, interests and concerns, and detect any shifting tides regarding views of business ethics and accountability. This paper provides a framework that organisations can use in making decisions that pertain to the public good and well-being.

\section{Background}

Each year companies around the globe, including Australia, experience crises that plunge them into disarray, generate substantial negative publicity, cost millions of dollars in lost sales, often cause stock prices to plummet, and, potentially, make the company an easy prey for take-overs. It is no longer a question of whether a major crisis will strike an organisation, but only a matter of when, which type and how (Mitroff and Pearson 1993). Only recently, the extortion threat to the Queensland company Herron Pharmaceuticals illustrates the vulnerability of companies to crises and the importance to the public good of their responses to it.

Many of us still recall the worst oil spill in history, when the Exxon Valdez tanker ran aground in Alaska's pristine Prince William Sound in 1989. The toxic shock publicity surrounding U.S. pharmaceutical giant, Procter and Gamble's Rely tampon resulted in an immediate $\$ 50$ million loss, while the Johnson and Johnson Tylenol capsule recall and subsequent equipment retooling cost that company a quarter of a billion dollars (Shrivastava, Mitroff, Miller and Miglani 1988). The chemical accident at Union Carbide's pesticide plant in Bhopal in 1984 killed 2,500 people and injured over 200,000. Consumers retaliated and Union Carbide's stock price subsequently piummeted (Shrivastava et al 1988).

In recent years, Australia has experienced a spate of crises including the Mettwurst contamination at Garibaldi Smallgoods, the 1998 Esso gas explosion and subsequent gas crisis in Victoria, the 1998 Sydney water contamination, and the 1999 Olympic ticketing fiasco. More recent crises include the Mobil aviation fuel contamination in February this year that grounded 5,000 light aircraft (Sunday Herald Sun 6.2.00) causing a potential business loss of $\$ 100$ million (Australian Financial Review 2.2.00), and the above-mentioned lacing of a Herron drug by an extortionist.

\section{What is a crisis?}

Crisis situations are defined as incidents that fall under close media or government scrutiny, run the risk of escalating in intensity, interfere with normal business operations, jeopardise the company's positive public image and damage the bottom line (Fink 1986). The cause of the crisis often centres on faulty decisions, inattention to emerging problems and neglect of ethical or social responsibilities (Ginzel, Kramer 
and Sutton 1992). The term 'crisis event' is used for the acute phase of the crisis when the problem erupts into the public through media coverage. Following the crisis event, public confidence in a company or its products needs to be restored to prevent a further crisis from occurring where the market translates its concerns into buying behaviour (Smith 1990). Failure to stem the tide of consumer retaliation may cost a company its continuing existence.

With crisis events hitting Australian companies each year, the question arises as to why some crises affect sales more than others. For example, the Garibaldi Mettwurst contamination - which resulted in the death of a four year old, hospitalisation of a further 22 children, the illness of 150 people, and manslaughter charges against three former company directors on (Adelaide Advertiser 12.7.96) - resulted in an industry-wide slump in sales of manufactured meats. In this paper, we argue that the general level of consumer 'involvement' with the crisis helps to 'determine how angry consumers become with the company concerned, which, in turn, influences consumer purchase intentions, and, ultimately, company sales.

\section{Weiner's Attributional Theory}

To understand how consumers react to company crisis situations and product failure situations, consumer researchers have applied Weiner's (1986) Attributional Theory. This theory argues that individuals make an appraisal of an event in order to discern its cause. In our earlier scenario relating to the Kraft peanut butter incident, the parent learned that the salmonella poisoning of her child was attributed to mouse droppings from peanuts roasted in Queensland. Once individuals make a judgment of responsibility for an outcome, they respond with either anger or sympathy. For crisis and product failure situations, researchers have discovered that causal attributions directly affect consumer anger, which in turn, negatively affects consumers' intentions to purchase the product in the future (Folkes, 1984; Folkes, Koletsy and Graham 1987; Jorgensen, 1994, 1996). These studies reveal that anger has a much stronger direct effect on consumers' repurchase intentions following a crisis than do their attributions about what caused the event. In other words, angry consumers stop buying company products, a phenomenon noted experimentally and observed following real life crises.

These studies reveal one limitation of Weiner's Attributional theory with respect to crises. It does not implicate emotions as the crucial precursor to consumer reactions. Instead, it focuses on attributions and its consequences.

Still, emotions do not explain the whole story. Indeed, we must ask: why does one consumer become angry at a situation that leaves another unmoved? Although he did not include it in the theoretical model $(1986,1995)$, Weiner did recognize that the essential determinant of anger intensity is the personal relevance of the event. Likewise, a study by Folkes et al (1987) showed that consumer anger increased as the importance to the consumer of the product failure increased. That is, the more personally relevant an event was to those observing it, the stronger their anger. Again, anger rather than attributions were the strongest predictors of consumer 
purchase intentions. The synthesis of this research underpins our argument that, following a crisis, anger will be determined by how personally relevant the event is to individual consumers. If it is your child who becomes ill from eating salmonellacontaminated peanut butter, or if you have a strong conviction about companies like Motorola that in the past produced microchips used in lethal landmines, then you may become angry with the company involved. We assert that it is when issues or crises are personally relevant to large groups of consumers that mishaps lead to plummeting company sales.

In sum, although attributional theory provides useful insights into the way in which consumer purchase intentions are affected, the theory focuses on explaining the consequences of arriving at a given attribution. It does not recognize that anger is crucial in explaining the reaction to crisis events and it does not depict the role of personal relevance in influencing these effects. Therefore Weiner's attributional theory, in its current formulation, fails to address two critical aspects identified in the studies of consumers' reactions to product failures and crisis events, namely anger and personal relevance.

We have argued elsewhere (Härtel et al, 1998) that incorporating attribution theory into theories that address these two important constructs is necessary to advance the study of company crises. The focus in this paper is limited, however, to the importance and role of personal relevance as captured by the notion of involvement with company crises.

\section{Weiss and Cropanzano's Affective Events Theory}

One theoretical model that includes personal relevance and considers emotions as central to explaining consumer reactions following a negative event is Weiss and Cropanzano's (1996) Affective Events Theory (AET). While this theory was specifically developed to explain the impact of events that elicit emotions and moods from employees in the workplace, we argue that it provides insight into how emotions elicited by crisis events directly influence consumer behaviour. The theory recognises that people can experience different emotions and mood reactions to events and that these different reactions have different behavioural implications (Weiss and Cropanzano 1996). It also, under appraisal theory, includes the concept of personal relevance to explain people's reactions to events.

\section{AET's application of Appraisal Theory}

All definitions of emotions incorporate the concept that people experience an emotion as a reaction to an event (Weiss and Cropanzano 1996). In line with most appraisal theories, AET suggests that events generate emotions through a two-part appraisal process with the primary or first level of appraisal determining the intensity of the emotion, and the second level resulting in the experience of different emotions, such as anger, sadness and joy. Under this first level of appraisal, theorists have recognised 
the importance of personal relevance. Here, we diverge from AET in suggesting that the concept of 'involvement' is more appropriate than personal relevance in explaining consumer reactions to a company crisis event.

\section{Primary appraisal}

Appraisal theorists, as well as Weiner in his Attributional Theory and Affective Events Theory, all agree that the primary appraisal of personal relevance of an event determines the intensity of the emotion experienced. What the theorists disagree on is what exactly makes up personal relevance.

Appraisal theorists like Lazarus, Smith and colleagues $(1988,1993)$ argued that people's appraisals consist of an evaluation of the significance of facts for their personal well-being (Leon and Hernandez 1998; Smith et al 1993).

Weiss and Cropanzano (1996) argued that the intensity of arousal is related to the 'event-implicated goal', its position in the goal hierarchy and its instrumental relationship to other goals. So the initial or primary evaluation contains an evaluation of the importance of the goal, which influences the intensity of the emotional reaction. Goals and objectives can be what people strive for, what they seek to avoid, what they hope to maintain, or what they want to see occur. Therefore, during a primary appraisal, the intensity of a person's emotional response depends upon how relevant the event is to a goal, how important the affected goal is and how inconsistent the event is to the relevant goal, since negative events produce stronger emotional reactions (Weiss and Cropanzano 1996).

While we do not deny that personal goals may be affected both in the workplace situations referred to by AET and in company crises, we suggest that goals are too narrow to apply to the broad range of personal concerns that influence consumer reactions following a crisis event. For example, consumer values or ethical concerns may be activated following human rights abuses or massive environmental pollution by a.company. Although AET did refer to values, goals are its main focus in primary appraisal. We now turn to two different conceptualisations of personal relevance.

Frijda (1996), in referring to goals, argued that emotions result from motives, values, beliefs and expectations. These concerns differ across individuals and groups and cover a range of areas including family health, economic security, injustice, shame, sense of belonging, self-esteem, and norm violation (Frijda 1996). Frijda believes that people appraise an event as helping, harming or threatening one or more of these concerns, and it is this appraisal that results in the type and intensity of emotion experienced. However, Frijda's notion of personal relevance appears to have gone untested.

A different conceptualisation is the construct of involvement, which has been used by consumer researchers to investigate personal relevance and establish measurement tools over the past 30 years. There is a large body of evidence supporting involvement as an important concept in understanding and predicting consumer behaviour. While involvement is usually applied to products and brands, 
consumers may be involved with many issues, including events (Peter and Olson, 1990) such as crises.

Research on consumer involvement identified three factors that determine level of involvement by consumers (Engel, Blackwell and Miniard 1993). First, there are personal factors such as the values, needs and interests that attract a consumer to an object (Zaichowsky 1985) or are important to achieve the consumer's goals (Celsi and Olson 1988). The second factor is temporary feelings of self-relevance that are caused by specific external physical and social stimuli (Zaichkowsky 1985). Third, involvement is affected by how a consumer responds to the stimulus or product. Usually, this dimension is used to refer to product characteristics, with products becoming more involving if there is some perceived risk (physical, psychological, performance, social or financial) (Jacoby and Kaplan 1972 in CraigLees, Joy and Browne 1995).

For example, if your child becomes ill through eating contaminated food products, or if you oppose companies exploiting the labour of children from less developed nations, you may become angry with the company involved. This involvement is activated as 'felt involvement' when an individual's intrinsic characteristics are confronted with appropriate stimuli. Felt involvement is a motivational state that energises and directs consumers' thinking processes and behaviours (Peter and Olson 1990, p. 86). The sources of felt involvement include consumer characteristics, product or stimulus characteristics, and characteristics of the situation. A number of consumer researchers view the level of felt involvement in a given situation as being determined by two sources - intrapersonal or intrinsic sources of personal relevance (ISPR) and situational sources of personal relevance (SSPR).

Intrinsic sources of personal relevance (ISPR) are relatively permanent elements of personally relevant knowledge, derived from a consumer's past experience and stored in their long-term memory (Celsi and Olson 1988). This knowledge represents associations between objects and/or actions and important self-relevant consequences such as the attainment of goals and/or maintenance of values (Celsi and Olson 1988). ISPR, through felt involvement, affects a consumer's motivation to pay attention to and understand information (Celsi and Olson 1988). The more involved a consumer is, the more she will attend to a message (Petty and Cacioppo 1983). During a company crisis, involvement could determine whether the consumer 'tunes in' to a message such as a news story on TV about the crisis, as well as the amount of attention paid to the message. These 'intrinsic' factors drive consumer behaviour such as search for information and attention and comprehension, determining consumer motivation to process messages about the crisis. As a result, we argue that in the company crisis event these intrinsic sources of personal relevance (ISPR) determine the consumer's motivation to attend to media messages about the mishap and process messages, including the company's response.

Yet even events that are extremely important to an individual are not personally relevant all the time (Celsi and Olson 1988). This feeling of personal relevance may only occur at certain times and in certain situations (Celsi and Olson 1988). Various cues, such as a radio news story about the crisis, may act as a situational source of personal relevance (SSPR). These cues are sources of felt involvement if they 
activate consequences for the consumer or the consumer's goals and values. Yet, because most situational factors are changeable, the felt involvement they create tends to be temporary. For example, in the case of the Exxon Valdez oil spill, media messages about the spill could have activated important personally relevant goals, concerns and values (i.e., ISPR) such as 'companies should be environmentally responsible' or 'Exxon should take responsibility for its actions.' In the case of the 1998 Sydney water crisis, the SSPR could activate beliefs (i.e., ISPR) like 'water should be safe to drink.' Repeated media coverage, therefore, acts as a reminder cue (i.e., SSPR), with each story reactivating the consumer beliefs, values or concems. However, if the crisis receives little publicity (reducing the situational source of personal relevance), then the consumer may forget about the crisis. In other words, the situational sources of personal relevance interact with the intrinsic sources of personal relevance to determine the level of felt involvement. This felt involvement, in turn, has an impact on consumer anger. We argue, therefore, that the degree of felt involvement determines the intensity of anger experienced in the company mishap. Anger may be intensified depending upon the extent to which media exposure (SSPR) impacts on the consumer's goals, values and beliefs (ISPR), therefore the anger-involvement relationship is reciprocal as illustrated in the model below.

Figure 1 Role of Felt Involvement in the effect of company mishaps on purchase intentions

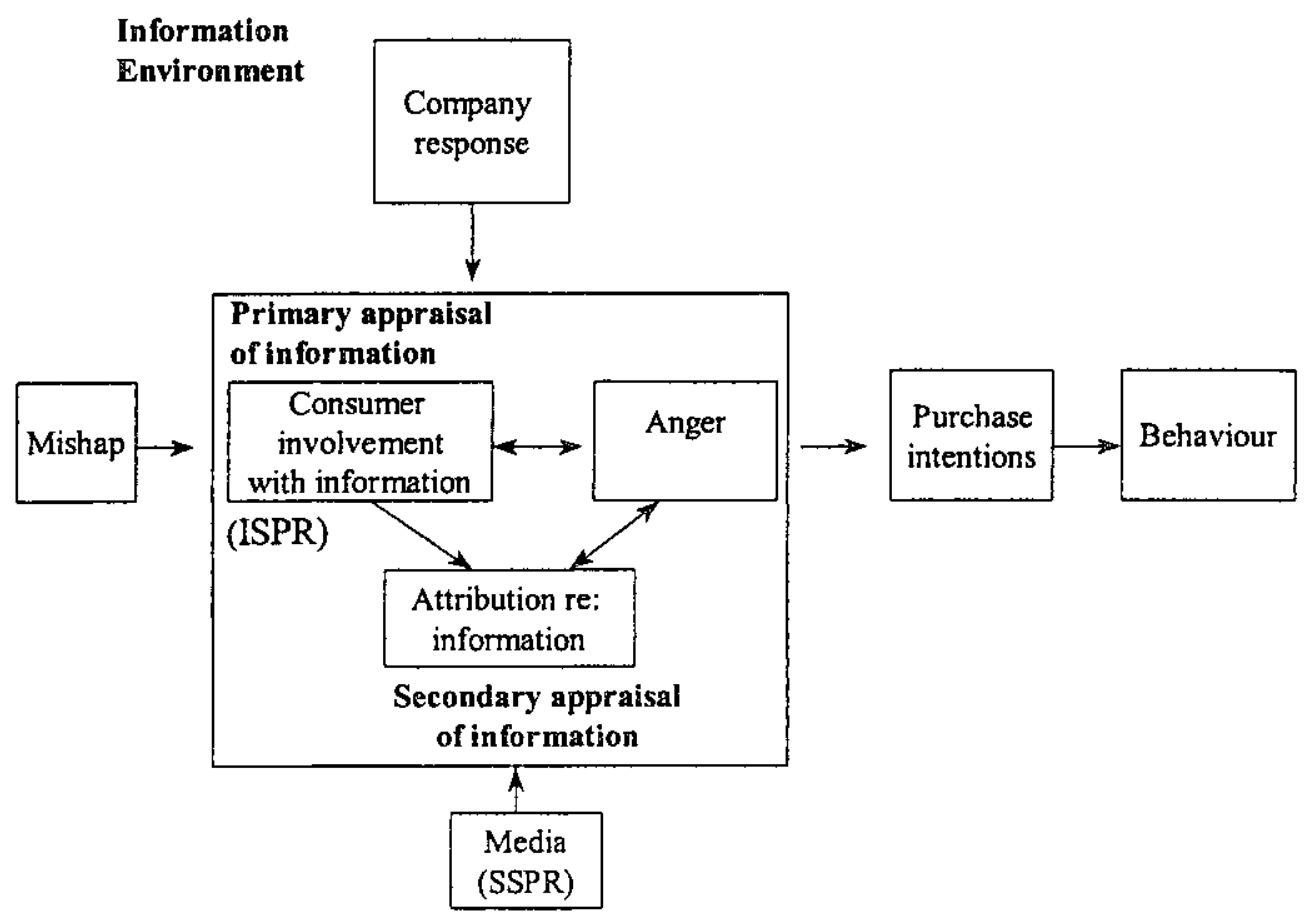


LYN McDONALD AND CHARMINE E.J. HÄRTEL

\section{Summary}

In line with appraisal theorists, Weiner's $(1986,1995)$ attributional theory and Affective Events Theory, we stated that following a company mishap the consumer conducts a primary appraisal of the personal relevance of the event which determines the intensity of the emotion experienced. Building upon the model of company mishaps proposed by Härtel et al (1998; cf. McDonald and Härtel 1999) we argued that this primary appraisal consists of a determination of felt involvement. We propose that felt involvement determines the level of processing of the mishap message, including company responses, as well as the experienced degree of anger intensity. Anger may be influenced separately by the degree of media exposure (SSPR) acting on the consumer's goals, values and beliefs (ISPR), and that therefore the relationship between anger and felt involvement is reciprocal. This model represents the first application of the concept of involvement to the study of company mishaps.

\section{Works Cited}

Celsi, R.L and Olson, J.C. 1988. 'The role of involvement in attention and comprehension processes'. Journal of Consumer Research 15: 210-224.

Frijda, N.H 1993. 'Moods, emotion episodes and emotions'. In Lewis, M. and Haviland, J.M. (eds) Handbook of Emotions. New York: Guildford Press, 381-403.

Härtel, C.E.J., McColl-Kennedy, J.R., and McDonald, L. 1998. 'Incorporating attributional theory and the theory of reasoned action within an affective events theory framework to produce a contingency predictive model of consumer reactions to organizational mishaps'. Advances in Consumer Research 25: 428-432.

Jorgensen, B.K. 1996. 'Components of consumer reaction to company-related mishaps: a structural equation model approach'. Advances in Consumer Research 23: 346-351.

McDonald, L. and Härtel, C.E J. 1999, December. 'Use of affective events theory to explain the impact of company mishaps on consumer anger and purchase intentions'. Refereed Proceedings of the $13^{\mathrm{h}}$ International Conference of the Australia New Zealand Academy of Management, CD. ROM. Hobart, Tasmania, Australia.

Weiner, B. 1995. Judgments of Responsibility. New York: The Guildford Press.

Weiss, H.M and Cropanzano, R. 1996. 'Affective events theory: a theoretical discussion of the structure, causes and consequences of affective experiences at work'. Research in Organizational Behaviour 18: 1-74. 